. Case study

\title{
Role of Media in Policy Making: Special reference to Afghanistan
}

\author{
Farooq Jan Mangal \\ Shaikh Zayed University Khost Afghanistan \\ Email:f.jmangal@gmail.com
}

\begin{abstract}
Mass media (Radio, TV, print...) plays a crucial and vital role in information distribution and thus in the political market and public policy making. Theory predicts that information provided by mass media reflects the media's incentives to provide news to different types of groups in society, and affects these groups' influence in policymaking. The study emphasize on the role of mass media in political markets and its effect on public policy-making. It attempts to develop a theoretical relationship between mass media and public policy. The empirical studies have tried to assess the effect of media on policy outcomes. Analyzing various cases in Afghanistan, media influences policy makers and higher authorities to act in accordance of the suggestion and recommendations of media workers and institutions. In recent decades, policy makers have considered on media's soft and proper demands based on their suggestions and recommendations, even many articles in Afghanistan's constitution would be amended. According to our findings, 'Access to Information Law', passed by president Ashraf Ghani, was a combine demand of policy makers, lawyers and media workers, who believed that legal information except the information that can harm national security should be accessible by locals and media workers through law. Similarly, Afghan Journalist safety committee developed a comprehensive policy against women Sexual harassment that will be discussed in the paper as a 'Case Study'. Hence, the policy has been accepted by Government of Afghanistan and is implemented since then.
\end{abstract}

Keywords: Online Teaching, Teaching Electronic Portfolio, Social Network, Facebook.

\section{Introduction:}

Mass Media (Visual, print or audio) exist primarily to deliver message content-entertainment, information, and advertisements to a vast and mass audience. Media act as a fourth pillar of the state. Hence, the channel (Platforms) delivers message to a mass audience is called mass media or primary mean of communication. Thus, Mass media is communication - whether written, broadcast, or spoken - that reaches to a large audience However at international level, particularly in developed countries, people depend on neutrality of media and freedom of expression but the revolution of France in 1968 reshaped the role of media. Those who criticized the revolution of France they noticed that during the revolution media played an important and vital role and according to their expression it paved the way towards the revolution and brainwashed common people. Besides this media has also played a significant role on the issues of Watergate and Richard Nicolson. Since the media act as channels of communication, it is important to determine whether they are politically biased in their presentation of information. If they are biased they may distort the concept of Democracy. Because they may, in such cases, only serve to manipulate rather than illuminate social problems. Media should be thought of as both carriers and delivery systems. They carry advertisements and deliver them to individuals who buy or choose media first on the basis of the kind and quality of entertainment and information and second on the kinds of advertisements they deliver. Advertisers find media to be convenient and relatively inexpensive delivery systems compared to 


\section{Farooq Jan Mangal et. al/ Role of Media in Policy Making: Special reference to Afghanistan}

direct mail or other channels that do not carry entertainment and information. Thus, the definition applies to online media as well as traditional mass media - the banner ads on websites and the sponsored links that accompany paid search keywords serve the same function as the commercials and printed advertising that accompany information and entertainment in traditional media. It is important to recognize that consumers have specialized needs that both mass media and social media can meet, by providing information about certain kinds of products and brands. Readers can browse a magazine or1) newspaper, stopping to look at any advertisement that seems interesting. When there is a clear need for information, 15 minutes spent with google, bing,2) wikipedia, and the other search engines will give a3) person top-line knowledge about any topic on earth. Advertisers who want to reach both a mass and a specialized audience find it is more expensive to buy media that reach the specialized audience. However, no matter which kind of audience advertisers want to reach, it is imperative that someone plans the purchase of media as far ahead of publishing or broadcast dates as possible. Advertisers cannot afford to buy media impulsively or capriciously. Therefore, the planning function is a major operation in advertising and media agencies and at client companies. Sometime two words (medium \& vehicle) use as a word which has same meaning. They are not exactly the same. A medium refers to a class of carriers such as television, newspapers, magazines, and so on. In other words, it refers to a group of carriers that have similar characteristics. A vehicle is an individual carrier within a medium. For example, the website cnn.com is a vehicle within the online medium. " 60 minutes" is a vehicle within television. Martha stewart living and people are vehicles within the magazine medium. In the mainstream policy change literature, the media's role is empirically underdeveloped and contradictory. The media is, at times, identified as a conduit for political actors and policy entrepreneurs in the policy subsystems to disseminate policy beliefs and, at other times, acknowledged as a contributor, pursuing policy beliefs in its own right to influence policy change. Both policy and communication studies would benefit from a broadened perspective of media influence. Political communication should consider the role of the mass media beyond just the formation of public opinion. The media as an institution is not effectively captured in a linear model of information signaling because the public agenda cannot be complete without an understanding of the policymaking agenda and the role of political elites. And policy scholars can no longer describe policy process without considering the media as a source of disproportionate allocation of attention and information. The positive and negative feedback cycles that spark or stabilize the political system are intimately connected to policy frames and signals produced by the media.

\section{There Are Three Major Duties And Responsibilities Of Mass Media:}

Providing information regarding political, social, and economic issues happening on local, regional and international level.

Lead locals on a right and correct path.

Wholesome entertainment.

The respective three aspects explain the duties and responsibilities of mass media needs an extensive explanation. Hence, it cover neutrality, impartiality, accuracy and other significant values of journalism.

\section{Background:}

Afghanistan has over a hundred year long history in journalism but the route of journalism is still unstable and unclear. The publication in Afghanistan initiated with the arrival of first printing press (lithography printing) from india in 1873, in 1873, saed jamaludin afghan with the support ofemir shir ali khan and published their first issue of shamsulnehar. Shamsulnehar was a periodical that publishes around 40-48 issues. [1] on January 11/1906, the second periodical, seraj-ulakhbar, was printed. Seraj-ul-akhbar was critical of the friendship between afghanistan and the united kingdom and was against the idea of colonialism. Thus, it publication stopped after the first issue. The newspaper resumed in 1911 by mahmoud tarzi, known as "father of afghan journalism". Mahmoud tarzi, was the editor and owner of saraj-ul-akhbar. In 1919, under king amanullah khan, seraj-ulakhbar was replaced by aman-e-afghan, serving as key organ of the government. At the same time some other smaller private journals appeared under different ministries. Along with these developments, radio broadcasting began for the first time in 1925, which greatly added to mass media. amin tarzi, in his article in 2006 to rfe/rl described afghanistan's independent media history. Afghanistan's first experiment with an independent media sector began in the late 1940s and was restricted solely to the newspapers. Prime minister shah Mahmud allowed relatively open elections and the establishment of 
Farooq Jan Mangal et. al/ Role of Media in Policy Making: Special reference to Afghanistan

what has come to be known as the "Liberal Parliament."The new legislature soon passed a press law that led to the launching of several newspapers that the monarchy, the prime minister, or both. Conservative religious figures and their supporters in the government were the most frequent targets of attack. The experiment ended abruptly in 1953 when Mohammad Daud Khan became prime minister and ordered the closure of independent newspapers. The country's second major experiment with independent media began with the promulgation of the 1964 Afghan Constitution by King Mohammad Zaher. That document ushered in what is commonly referred to as Afghanistan's "decade of democracy." The constitution decreed that "every Afghan has the right to express his thoughts in speech, in writing, in pictures, and by other means, in accordance with the provisions of the law." The 1964 constitution further states that every Afghan has the right to print and publish ideas in accordance with the law without prior screening by state authorities.The government soon promulgated the 1965 press law to regulate the media sector. That reiterated the constitutional guarantees, but it also forbade obscenity and any "matter implying defamation of the principles of Islam or defamatory to the King." While broadcast media remained the prerogative of the state, the number of independent newspapers mushroomed under the new legal framework.The next media shake-up came in 1973, after Mohammad Daud led a coup d'etat overthrowing country's monarchical system. The result was nearly three decades of intense structures on a free media, culminating in the hard-line Taliban regime's crackdown until it was ousted by international military intervention in late 2001.The 1964 Constitution of Afghanistan and the Press Law (1965), insisted on free press, within the boundaries to respect Islam and behave appropriately. The press was editorially independent from the government but it was instructed to safeguard the interests of the state and constitutional monarchy, Islam and public order. Afghan journalism widely progressed and developed from 1950s through to the 1970s, though it remained limited. When the government was overthrown in July 1973 coup and 19 newspapers were shut down and media came under severe restriction, ending a period of relative freedom. [20]

The first colour television broadcasting appeared in 1978 during Sardar Muhammad Daoud Khan's era. Then media fell into the control of Soviet influences during the Soviet invasion of Afghanistan in
1979. The media has mainly been very limited under the Taliban Regime, including the banning of television in 1996, seen as "morally corrupt", and music, banned under their law.During the era, Taliban destroyed the television sets and studios. Also, anyone who got caught with a television or listening to music was subjected to imprisonment and punishment. During this era, most media operated from other countries. Majority of the Afghans listened to BBC Persian operating from London and Pakistan as the most trusted source for their information.In early 2002, a relatively free diverse media emerged. The participants of the national Jirga (gathering) held in 2002 about the constitution of Afghanistan, declared articles about the media too and recommended a committee to further develop a law for media. In the last ten years, a lot of media emerged but the quality is still a question. Also, the media is still controlled by the Mujahedeen's and warlords. According Afghan Journalists Safety Committee since 2001, several hundred print and electronic media have been established and collapsed. [4]

Here are the figures of print and electronic media across Afghanistan provided by Afghan Journalists Safety Committee.

\section{TV channels: 75}

\section{Radios: 175}

News Agencies: 10

Print (Newspapers, weekly, monthly, timely, quarterly...): 1700

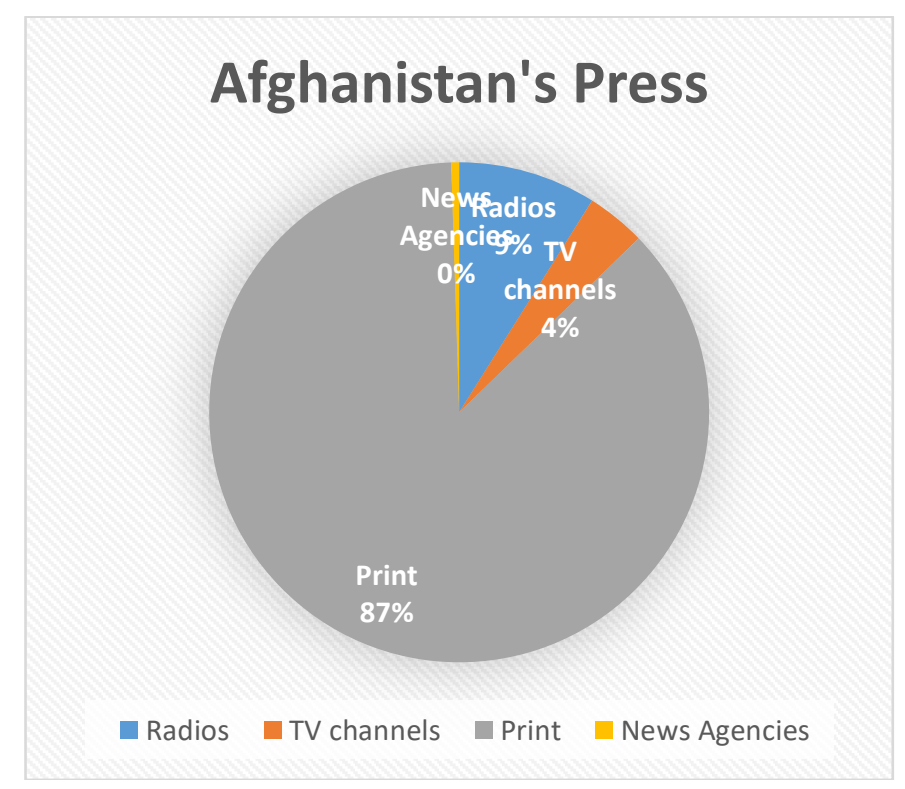

Figure 1

The figure shows the number of print \& electronic media in Afghanistan [2] [21] 


\section{Role Of Media In Policy Making Media And Public Policymaking}

The policy literature has yet to satisfy the ongoing debate about whether media are simply a conduit for information about the policy process or a cause of policy change. As a conduit in the policy process, media transmit multiple viewpoints characterizing the policy debate to a wider audience; as a contributor, media advance a particular policy agenda. [9] These influences can be direct or indirect; they can be obvious or innocuous. These approaches have been explored gradually in the literature on media and public policy, but typically, they are reported as separate "media effects" under topics such as priming and framing agenda setting the use of language and rhetoric and issue definition. In exploring each issue in-depth, these literatures (understandably) fail to cast a broader view on media's roles. Yet, not all studies have taken this route. Authors such as Baumgartner and Jones (1994) and Cobb and Elder (1972/1983) note that the media's reflection of public policy tells us a lot about the broader policy process that we may not otherwise glean from studies that focus exclusively on individual policies. An in-depth look at specific policies or networks of actors tells us a lot about those particular policies and actors, but it may fail to give us insight into the larger context in which those policies and actors are situated. Such studies may take too narrow a view of a necessarily broad subject. As such, typical approaches to policy studies miss out on the high level view of the policy process, leaving a gap to fill in policy research. Leveraging media's consistent reflection of the policy process as a data source can help to fill that gap.[13]The contrast between direct and indirect media effects is not clearly delineated in the literature on media and policy. However, it is reasonable to state that direct effects are those ways in which the actions of media impact individuals who make public policy. Indirect effects, on the other hand, are the collection of instances whereby media convey a message that influences the inputs to and outcomes of public policy via the public. Most of the attention to media's effect on policy is focused on indirect effects such as opinion representation and how media shape people's opinions about policy. However, there are other ways in which media impact policy; media can (and often do) shape the realities of policymakers themselves.
Roles Of Media: The Conduit - Media's Direct Effects:

Media can influence political elites and policymakers directly. Zaller argues that public opinion is heavily influenced by exposure to elite and media discourse, policymakers are also affected by media discourse. The relationship is reciprocal, however. In order for the media to have a direct influence on policymaking, a few conditions are necessary: politicians have to receive and internalize the media's message, politicians' preferences have to be subject to change, and media have to put out conflicting, dissenting or alternative information to the policy status quo. Certainly, in any modern liberal democracy, it is accepted that politicians and policymakers are avid consumers of media content if for no other reason than to receive information on their own performance. [14] [10] The second criterion, whether politicians' preferences are subject to change, is well established in the policy opinion responsiveness literature (discussed below). The third criterion, the presence of conflicting, dissenting or alternative information to the current status of policy, has been documented by the work of Schatt schneider, Cobb and Elder. Why and under which circumstances do politicians actually react to media's input on policy? Eilders notes that, in most cases, media affects individual politicians in the same way as ordinary citizens; they act on media cues to communicate with one another and with the public. This is to some degree tempered by the personal traits of political actors and the specialization or prominence of political actors The more generalist a political actor, for instance, the more they will be driven by the media; specialized political actors, on the other hand, tend to focus more on their policy subfield, and are often neglected by general media coverage. Nevertheless, policymakers in general are some of the top consumers of media for the same reasons as the politically interested citizen; media can provide the most thorough and reliable coverage of political issues across policy domains and national contexts. Despite this, there have been few attempts to understand how media help to shape the policy decisions of policymakers. The policy sciences community has been able to point out that media may directly influence public policy, though the empirical links largely point to correlation rather than causation. Some scholars argue that media impact the policy process through an "insider" relationship with politicians. Even within these accounts, there is some uncertainty whether media 


\section{Farooq Jan Mangal et. al/ Role of Media in Policy Making: Special reference to Afghanistan}

are a conduit that reflects policy arguments within a given policy subsystem a contributor through its role as a part of an advocacy coalition of political actors or both.Therefore, we are left with strong assumptions that policymakers are influenced by media, but an incomplete picture of how this is done, and little way (short of experimental designs with compliant legislators) to show a strict causal relationship. Through the design, it is not able to extract a clear linear influence, given that policymakers in their very actions also influence media. While this question points to a necessary (if complex) future research agenda, we can still derive a good amount of information about the media's role in reflecting policy to the public. This challenge is taken up in this dissertation.

\section{Roles Of Media: The Contributor - Media's Indirect Effects:}

Similar to Shanahan et al.'s (2008) argument that media may serve as a conduit in the policy process, the argument for media's indirect effect on policy supposes that media influence individuals' opinions about policy and then transmit them more broadly. In other words, an indirect effect is a two-step process wherein media first, mediate the relationship between individual attitudes and policy, and second represent those opinions to policymakers. The literatures on what I refer to as "media effects" and the "policy-opinion link" provide the background on how these processes individually work. [19]

\section{Media Effects:}

Government responsiveness to public preferences is a key indicator of democracy. How the public views policy can have a great influence on the behavior of policymakers. Media's role in this relationship is well documented and was established early on in political research beginning with Lippman (1922), and expanded upon by Berelson, Lazarsfeld, and McPhee's (1954) Cognitive Effects Model. Their model contends that while people already have set ideas and opinions, media influence people's prioritization of some issues over others by showing stories in higher volume. McCombs and Shaw's (1972) work in the Chapel Hill study showed this to be empirically justified; at roughly the same time, Cobb and Elder (1972/1983) showed how the policy• agenda worked in roughly the equivalent manner.• While the early literature established that media do, in fact, influence public attitudes, further work has focused in on how this is done. The literature on the cognitive capacity of individuals to receive media messages sets out certain assumptions. First, it is clear that individuals' attention to anything is limited and finite, not to mention varied across individual.

Second, individuals' attention to policy-related discussions is limited to the small subset of relevant issues that are highlighted by the news media. Moreover, attention to policy is cyclical and often inconsistent. That being said, media do a reasonably good job at narrating events or storytelling often focusing on more palatable aspects of news.How attention to policy ebbs and flows is largely a product of three key elements in the discussion of media's illustration of the policy process: issue definition, framing, and the use of language and narrative in relaying policy ideas to the public. These things are often referred to as "media effects", however, these three phenomena can also be recognized as the consequences of having media. Each is explored in further depth below.

\section{Role of Media in Policy Making:}

In the public policy context, media is important because it "primes" public opinion. Media, in priming, establishes permissible limits to discourse and agenda. It creates awareness of issues and conveys its assessment of the degree of urgency. Media frequency and emphasis - tonnage and display - create a hierarchy of importance for public issues. [12] As mentioned above, mass media play vital and significant role in shaping and transferring the message to public. As policymaking is a political process which is affected by various social and economic factors and the medial play an integral and vital role in shaping the social context in which policies are developed. If government and policymakers made comprehensive and fruitful policies for the reconstruction and development of countries and prosperity of people and stay limited to their offices and cupboards it won't be an affective policy except those policies which should keep as a secret. Through the media, citizens and publics know that how government policies affect them. Despite formulation, agenda setting, evaluation here we highlighted and discussed role of media in some more important aspects of public policy.

\section{Access Of Public:}

Policymakers and government make polices for the development and prosperity of countries and its people. Citizens should know that how the policies of government affect them. How government makes 
Farooq Jan Mangal et. al/ Role of Media in Policy Making: Special reference to Afghanistan

policies for them. They know and get information regarding the programs of government and paveway for the implementation of government's policies.

In the past policies were manipulated to the benefit of the elites because no information reached people because channels of dissemination of information did not exist. Whatever sources of information were• under the direct or indirect control of these ruling elites. With mushroom growth of media both print and electronic, information has become easily available for the people. It is not easier any more for the vested interests to hide information. Thus, it resulted in transparency in the policy formulation.

\section{- Reaction}

As a transferring channel, media convey polices of government and policymakers to locals. Although government and policymakers know very well and. pay attention to local sensitivities but sometime. government faces with the reactions of people. Whenever local shows sensitivity with some programs and policies then government should bring changes and revise their policies. On the other hand, media is also a unifier of diverse viewpoints. At a time when a national policy may not be in accordance with popular appeal but it is in the larger interest of the country, it does educate the populace about the benefits accruing from adoption of such and such policy for the country. Such situations often arise on issues of diplomacy and foreign policy where policy has to be worked out keeping in view country's strengths and weaknesses not emotionally.

\section{- Identification Of Problems:}

The media influence in the problems formulation stage is enormous. The nature of the media is to report things to the public. Because of the daily reporting the media can bring many types of things and issues to the forefront of the conscious. This is crucial because when the media begins reporting on the issues of importance to people the policymakers tend to start listening. This is what starts the ball rolling, so to speak. The media can also report on issues that may not seem that critical, and by merely rousing interest it can make non-issue a major policy issue.

\section{- Implementation}

Before we implement policies, programs and plans of government we should pave the way for the implementation of these programs. Public awareness is the main and major responsibility of media. Media can inject a new idea regarding government's policies to people's mind.

Before a former cultivate maize, wheat or something else, he equalizes and prepares the surface of the field for irrigation. He works for hours and eventually achieves a good product.

\section{Feedback:}

Government and policymakers get feedback of their policies through media. Media workers make reports and cover different aspects of government's policies. At the result, policymakers and government structures receive new ideas. On the basis of media reports and exclusive programs policymakers bring improvement in their policies and will count on the output and outcome of their policies.

\section{Watchdog:}

Mass media can play vital role as a source of watchdog against violation of human rights and governing deficiencies.In doing so, media is critical to public and civic agenda setting. Most people accept that agenda and then tend to invest responsibility in their leadership to resolve the issues they have come to believe are both important and urgent. Leadership is then evaluated on the basis of the efficiency it displays in dealing with important issues. Curiously perhaps, that media influenced public agenda is not necessarily synchronous with an agenda voter would set independently. But research has shown that approval ratings conferred on politicians have more to do with their resolution of the media public agenda than their resolution of issues people might personally hold to be more important.As we all know, if we think about it for a moment, much of the work in Ottawa by media, politicians and officials has been essentially a struggle to influence the agenda setting exercise. However, in Canada today, there is far less social and civic premium being paid to the value of a shared national information experience, in effect the national agenda setting process. In part that is because of centrifugal pressures in a rapidly regionalizing society, in part it is true because media news definitions have expanded so substantially that it is hard to assemble coherent, mutually agreed upon hierarchies of importance - the traditional core of what people used to call News Value. "What happened today" is much more complex question than it used to be.News organizations have begun to reject their professionally articulated mandate, that 


\section{Farooq Jan Mangal et. al/ Role of Media in Policy Making: Special reference to Afghanistan}

of establishing and communicating Importance, to a much more commercially viable mandate of communicating issues of relevance and interest. The broader the range of issues, the more emotional, divisive, entertaining and interesting those issues are, the larger the prospects of assembling new coalitions of audience. However, by definition, that broader range of issues yields a series of eclectic choices made for different target audiences, rendering each news agenda idiosyncratic. We have had, and will continue to have for a while, a situation where mass media is the main source of information for most people; it determines its news agenda by commercially driven criteria; that news agenda is understood by the electorate to be a public policy agenda and leadership is evaluated by the electorate and a sometimes hostile media by the way it hews to, and resolves, that agenda. So at this point, let me move ahead to the real core of this discussion, the interplay among media, government and public policy. The coverage of power and leverage. The exercise of power and leverage through government and public policy has always attracted journalists because of the "special role" they have adopted for themselves. That is the role of media as public watch dog, as the arbiter of accountability. It sometimes is expressed in the wonderfully telling phrase that media's job is to "afflict the comfortable and comfort the afflicted." It was what helped create an agenda of "intrinsic importance"- economics, politics, finance. Abuse of power has been a legitimate target for decades for the same reasons. Now, however, coverage of power has become not so much a content marketing tool as a crucial tool for corporate positioning. The process from Meech Lake to Charlottetown and the national free trade debate reconfirmed to media that a dispassionate assessment of power, an emphasis on intrinsic importance, could put it on the "wrong" side of the gulf between elites and those who feel disempowered and alienated. Mass media has moved from reporting and evaluating to trying to represent and empower its audience. It has understood that people are alienated and suspicious and it has begun to pander to those feelings both by reinforcing the reasons for alienation and suspicion and by acting as a voice for the alienated and suspicious. Its quest to represent and its fear of being on the "wrong" side has led it to not only be suspicious of power and its exercise, it has led to a suspicion of expertise because that is seen as a tool of the powerful. It is no accident that mass media emphasis tends to concentrate on "ordinary" people and their preferred options and solutions. Remember that media are highly consumer sensitive, and they are reacting to public opinion and marketing realities.In a complex and threatening world, an alienated citizenry wants control over what may threaten it or the ability to wreak retribution. People do not want to believe that things happen haphazardly or randomly. They don't want to believe that things can't be easily fixed. They want to believe that someone is in charge and more to the point, that if someone were truly in charge, the world would become safe and comfortable again. To make that construct work, someone has to accept responsibility if things go wrong.In response, since most journalists don't care about the institutional or systemic impacts of their work and since they are not terribly interested in technical issues, they are happy to lead the search for blameworthiness because it is a better story. On the whole, the public has a pretty good idea what it wants. It doesn't know much about how to get it and it certainly doesn't understand and accept real world constraints. Impediments like jurisdiction meet with angry impatience. Intellectual understanding of the difficulty in providing comprehensive quick medical care doesn't reduce the emotional angst of being on a waiting list. The inability of leaders to admit error or uncertainty does not inspire confidence. The years of acrimonious public debates on a variety of critical issues involving stakeholders, interest groups, activists and leaders have exhausted the public patience for resolutions that are the product of loud and angry partisan and ideological dialectic. And though media understands there is a public demand for solutions and quiet collaborative partnerships, and it understands it has lost the confidence of the public as it appears to be exclusively negative, it also understands that the public likes its media to act out the public's generalized sense of grievance. Media believes those conflicting impulses may be irreconcilable and goes with what it believes entertains and sells. As a result, at the risk of oversimplifying far too much, there are basically two legislative systems in Canada. - the first is the system that has evolved over time and that functions reasonably well. It is the elite brokerage and resource allocation process of classic political science texts. The other is the system that kicks in once mass media enters the process, a system that often becomes dysfunctional and spins out of control. People involved in governance, whether directly, or trying to influence it, tend to think that media has a responsibility to inform and educate 


\section{Farooq Jan Mangal et. al/ Role of Media in Policy Making: Special reference to Afghanistan}

and to act as fair witness to the process. Actually media has no interest in, nor the ability, to become a more effective link in the process of governance. Though journalists tend to accept their responsibility in fostering democracy and generally tilt towards support of western political systems, they feel no real attachment to or support for current institutions themselves and certainly not for many of the traditions and conventions of those institutions. People often forget that though their own issue is all-consuming, political reporters work in a wider overall context. They try to fit virtually everything within the dramatic narrative which is the ongoing political context - the current level of success and viability of the government in power. Every issue has the potential of advancing a government's interests or setting it back, of testing a Minister's competence and popularity. Sometimes, to media the importance of issue resolution is not the actual substance of the resolution but the way in which it was accomplished and the political consequences it has set off.An intuitive understanding of the competitive interests of media and the impact of media "frenzies" usually leads, in government, to risk avoidance, careful communications planning, secrecy, a difficulty in discussing or disclosing options. It also leads to a paranoia about interest groups and public lobbying because they turn the spotlight onto divisive issues. Put a bit more generously, government has far more room to man oeuvre and far more flexibility when it can sort out competing demands relatively quietly. When media becomes involved, the rules change.

Government (political and bureaucratic) and media too often see themselves as permanent residents locked in a difficult and perhaps mutually destructive ritual dance. Interest groups and stakeholders are seen as transients and their issues are usually, depending on their visibility, just agenda items on day timer lists, or temporary battlefields to move into and out of. To extend the metaphor a bit, competing groups and issue stakeholders often become surrogate forces for the real competitors, government politicians, officials, opposition parties and media. What are more appropriate roles and practices for media and the institutions of government? Everyone knows what they should be. Fostering an open system with the ability to discuss options, tell the whole truth and encourage informed debate and dialogue. Where mistakes are simply mistakes; where opinions can change and evolve, where accountability is clear, where every issue does not assume deep political consequence. We need to lower the stakes. The clear road would involve desensitizing and depressurizing the system. [14] However, there may actually be no incentive for media to change because there is no indication that there is a real public willingness to engage in public policy and its issues. And that is a truth few want confront.

Policymaking is a political process which is affected by various social and economic factors and the media plays an integral and vital role in shaping the social context in which policies are developed. Through the media, citizens and local people know and learn how government policies will affect them, their lives, and governments gain feedback on their policies and programs. The media acts as the primary and basic conduit between those who want to influence policy and policymakers controlling the scope of political discourse and regulating the flow of information. Policymaking follows an orderly sequence where problems are identified, solutions suggested, policies made, implemented and lastly evaluated. In reality, the policy process is more fluid, where policies are formed through the struggle of ideas of various advocacy coalitions. The policies, on which the media focuses can, and often does, play an important role in determining the focal issues for policymakers.[22]

One of the fundamental and basic roles of the media in a liberal democracy is to critically scrutinize governmental affairs: that is to act as the 'Forth pillar' of government to ensure that the government can be held accountable by the public. However, the systematic deregulation of media systems worldwide is diminishing the ability of citizens to meaningfully participate in policymaking process governing the media. The ensuing relaxation of ownership rules and control, has resulted in a move away from diversity of production to a situation where media ownership is becoming increasing concentrated by just a few predominantly western global conglomerates. Obvious problems arise for democratic processes, when huge media conglomerates also fulfill the role of powerful political actors; their close links with the corporate economy are widely considered to limit their ability to investigate the government and represent all points of view. The media are active participants in the policymaking process and the ability to stimulate change or maintain the status quo depends on their choice of subject or policy issue and how they frame it. Active (investigative) reporting attempts to shape policy outcomes, but this does not necessarily mean that it always represents the most 


\section{Farooq Jan Mangal et. al/ Role of Media in Policy Making: Special reference to Afghanistan}

successful approach for gaining policy changes. In fact, sometimes passive (straight) reporting can have a greater influence on policy choices. When this occurs, media independence is largely bypassed, as the news generated depends solely on the information released (as public relations material) from legitimate news sources. The media may also influence policy outcomes through their ability to exclude certain policy options from the media, which sets the boundaries for legitimate public debate. Such analyses have led some researchers to posit that the media has a powerful monolithic influence on all policy processes, while others suggest it plays an insignificant role in policy making processes; a more likely scenario is that its degree of influence varies considerably, being issue based in nature.

\section{Media Selection Of Legitimate Policy Actors:}

The media acts as a powerful political actor, with its interests strongly tied to the status quo and that of other corporate policy actors, instead of the general public. Journalists and editors shape policy agendas by actively filtering issues, so that reporting conforms to their dominant news values - selecting what issues are covered and which sources are used. This tends to confine policy debate to the strict boundaries of current accepted wisdoms set by the major political parties or institutional policymakers. The conservative nature of these perceptual screens is strengthened by the media's need for concision, which is especially dominant on television, with its appetite for sound bite politics. Creation of credible policy frameworks influence journalists in much the same way, leading them to rely on institutional actors (encountered on daily beats) who support their perceptions of a successful policy framework.[22]Development of such close relationships with sources is very important to the policy process, and often results in what is described as "coalition journalism" . Support for policies is also reinforced by, (1) credentialing supportive sources and disregarding opposing sources, (2) using labels to shorthand information about policies by placing them within frameworks (with their associated assumptions), and (3) by the way sources are then in a sense forced, to reflect these perceptions accepting the commonsense interpretation of these policy frameworks to protect their own reputations in the mass media.Outsider groups find it difficult to voice opinions in the media and even when they do, official sources are contacted to balance these stories to ensure objectivity. These, often resource-poor groups, are compelled to use the media as a means of gaining recognition as trusted policy actors. However, due to the media's reliance on established sources they may need to resort to different methods to capture media attention - which may cause distractions to their legitimacy, as the news may focus on a group's event and not its politics. Media stereotypes of policies, individuals or groups can influence their respective abilities to determine policy outcomes. Furthermore, even if certain policies turn out to be successful, they may still be subjected to unnecessary reform, if their legitimacy has already been undermined in the media by the creation of negative stereotypes. Furthermore, is often difficult for citizen campaigners to reframe official policy frames once they have been adopted by the media. Even if the media can set the actual policy agenda in some circumstances, this does not necessarily mean that they influence policy. Political rhetoric may appear to signal media impact, but if it does little more than pay lip service to media coverage, effecting only minor policy outcomes, then to what degree has the media really affected the policymaking process?Media coverage actually has limited consequences for actual policy decisions even when policy agenda and political discussions are affected by the media. The media is important for understanding the political agenda and the framing of decisions about special or sensational issues, but normal politics and the broader policy priorities or governmental issues are largely unaffected. Media influence is strongest with sensational issues, and weakest in governmental issues, which are predominantly policy-driven. Likewise, when a policy issue is nonrecurring in terms of media coverage (a sensational issue), media power to influence public opinion (but not necessarily policy outcomes) is greater than with recurring policy coverage (which are more synonymous with governmental issues).In the past it was believed that the media's influence on policy occurred in a straightforward fashion, with journalists clearly separated from the governing processes. Media investigations (initiated by popular public sentiment) prompt widespread changes in public opinion, citizens then organize and collectively pressure the government, which capitulates to popular pressure and makes the appropriate public policy reforms. This simple linear model has recently been described as the 'Mobilization Model' - while in the past it has been referred to as a 'Popular Mobilization' or 'Public 


\section{Farooq Jan Mangal et. al/ Role of Media in Policy Making: Special reference to Afghanistan}

Advocacy'. This model assumes a strong democratic role for citizens in policymaking processes, a role which has been disputed by a number of political scientists who suggest that special interest groups and other political elites dominate the policymaking processes, not the public. Policymaking changes often occur regardless of the public's reaction" to active (investigative) reporting. Prepublication collaboration between the two groups (journalists and policymakers) may be the real driver of policy agendas, not public opinion. Prior knowledge of upcoming media attention often enabled policymakers to exploit negative media attention as policy opportunities. In this way, policymakers are able to manage their media coverage to maximize positive publicity for their policies. This symbiotic relationship, entailing active collaboration between journalists and policymakers to determine policymaking agendas has been described as "coalition journalism" and would seem to stand in total opposition to the commonly perceived adversarial nature of investigative journalism. The media has become a vital force for legitimizing governmental institutions and free enterprise. Both parties gain by participating in coalition journalism; journalists obtain credentialed information and recognition by providing an important legitimate story, while policymakers obtain publicity for their policy agendas. Perhaps the only loser is the public, who ends up losing challenging adversarial forms of journalism. The amount of time being spent by muckraking journalists on investigative reporting is not declining. However, there is a trend towards shorter investigations which, taken together with cuts in funding for longer term investigative reporting, is placing increasing pressure on journalists to replace adversarial journalism with coalition journalism. Investigative journalism is becoming less visible in the public sphere, as its work becomes more widely dispersed, conventional and less adversarial - staying closer to the borders of the dominant policy discourses. A further outcome of these changes is that as shorter investigative pieces are cheaper to produce, media outlets have less incentive to actively pursue policy stories for the duration of policy processes. Dominant news values, such as timeliness further strengthen such practices by working to constantly change those issues on the public agenda, preventing any form of sustained media attention to most issues.Media corporations may set policy agendas, but as the duration of policy attention cycles continues to decrease, influence of policy outcomes will be increasingly left out of reach of the public, and safely in the hands of established policymakers. So as coalition journalism becomes more institutionalized, the general public is being pushed further towards the margins of the policymaking processes, left ever more prone to manipulation from both the media and policymakers. It is easy for the media to mislead viewers regarding the success or failure of say environmental policies: creating unwarranted pressure for policymakers, who may feel the need to alter effective policies to safeguard their public standing, or preventing other policymakers from seeking solutions to ineffective policies. These media effects on politicians are amplified if timed to occur just prior to elections, especially if the politician(s) in question does not have clear public support.For much of the time outside electoral campaigns, the role of the media in policymaking is more connected to the manufacturing of elite rather than mass forms of consent. The primary target of media coverage is an elite audience, who can directly influence policy, and the secondary target is public opinion. Manufacturing of elite consent also seems to be the main purpose of coalition journalism which primarily serves policymakers and media interests, before the public. Media corporations, acting as powerful corporate bodies, engage with credentialed policymakers to set both policy agendas and the legitimate terms of discussion. If there is sufficient disagreement, as to the terms of the debate among major political parties, then a fierce public debate can ensue under such limited conditions (confined that is within conventional truths). However, where official opposition voices are united, it is unlikely that the media will challenge them, and policy issues will be strongly framed to support official policy positions.

\section{Role Of AJSC (Afghan Journalists Safety Committee) In Policy Making: Introduction Of AJSC:}

Afghan Journalists Safety Committee (AJSC) is an independent, nonprofit organization that supports press freedom in Afghanistan. AJSC work towards the advancement of journalist safety and rights so that they can report in a safe and fearless environment. AJSC is based in Kabul and maintains a presence in every province of Afghanistan.AJSC was formed based on the recommendation of Kabul Conference on Freedom of Expression, which was organized in March 2009 by International Media Support (IMS).AJSC has a board of advisors composed of well-known media workers and 


\section{Farooq Jan Mangal et. al/ Role of Media in Policy Making: Special reference to Afghanistan}

civil society activists. AJSC's executive section has official representatives in eight regions of the country and an unofficial focal point in the remaining 26 provinces. This has enabled AJSC to establish representation throughout the country and provide media workers with necessary help when needed.[21]

\section{Afghan Journalist Safety Committee: The Policy For The Prevention Of Sexual Harassment:}

Sexual harassment is one of the common problems for women. Nevertheless, Women face various problems like, honor killing, rape,domesticproblems and sexual harassment. All women, literate or illiterate, old or young, rich or poor faced such problems in places like, villages and towns, markets as well as in public service places. Though Mass Media is based on social and political wisdom and the estimation of sexual harassment need to be existed at lowest point; but unfortunately it's far away to exclude every government or nongovernment administrations. Afghan government provided some appropriate recommendations ${ }^{\bullet}$ considering the values in the framework of the constitution and other subordinating laws for $\mathrm{a}^{\bullet}$ secured and safe family and society which need to ${ }^{\bullet}$ be protected from every kind of harassment and violence. With the existence of the implacable laws ${ }^{\bullet}$ and rules unfortunately, still the private and public service administrations are not free of harassment. The compilation of the anti- sexual harassment policy is aimed to spread the culture of professional organizing to pursue equilibrium with the values of the society. Those values include the selection of the rational alternatives for supporting of their huge participation and support of them at managerial level.

\section{Introduction to the Problem:}

The Afghanistan Independent Human Rights Commission (AIHRC) published a report in 2013 that deals with the factor of prevention for the creation of oppressive sexual clichés, complete introduction of the victimized of the incident. It alsocarried out research about the social and cultural activities which result in the prevention of the violence and become customary towards women. The independent commission pointed to some clichés where women have been known as defective creature. And these clichés are widely included in daily routines of Afghan people. Same time research of an instructive and training centre carried out in 1396 suggests that $65 \%$ of women faced sexual harassment in working environment. [2]
The ministry of women affairs said in a report which was published some time earlier, the hurdles towards women's job in government and nongovernment administrations, lack of opportunities in leadership, nationalism in employment affairs, lack of professionalism in work, spreading of rumoursin working environment, the absenteeism of separate possibilities for women and joint work place for male and female workers are called the main obstacles towards women's employees.

The research centre for women and children suggested that $90 \%$ of harassment took place in public places, $87 \%$ in working environment as $38 \%$ of it verbal harassment and $25 \%$ was non-verbal harassment. Based on the available data, the report shows that $29 \%$ left their job in reaction and $6 \%$ showed physical reaction. These numbers showed negative impression on the consistency of the work, and $44 \%$ of women viewed negatively in the working environments. Hence, it result in the following interferences:

Leaving work

Increasing of stress day by day

Isolation

Creation of negative view about the working environment

Even the report published by New York Times investigated all other dark aspects of the report. Though the report called the harassment as social problem, still having some stories in media.

Here female journalist states their bitter experiences but due to security concerns victims rejects sharing of such stories with media. The stories of victimized are very painful and having necessity for serious plans and creation the policies. Media and other foreign administrations published less or more reports about sexual harassment of different families cause of various issues like, cultural limitations, lack of information etc.The report which was published by Afghan journalist safety committee in 2016 from Kabul, Balkh, Nangarhar and Herat provinces explains that the female workers of the media suffers from the existence of sexual harassment.[4] In this report $59 \%$ of respondents confirmed sexual harassment by their co-workers and $41 \%$ of the respondents said that they were harassed in live programs or by the called guests for the programs. $69 \%$ of the respondents were harassed and $31 \%$ of them were not encountered with such a harassment. One of the factors of female journalist's sexual harassment is the 'silence of the victimized'. [2] [21] 


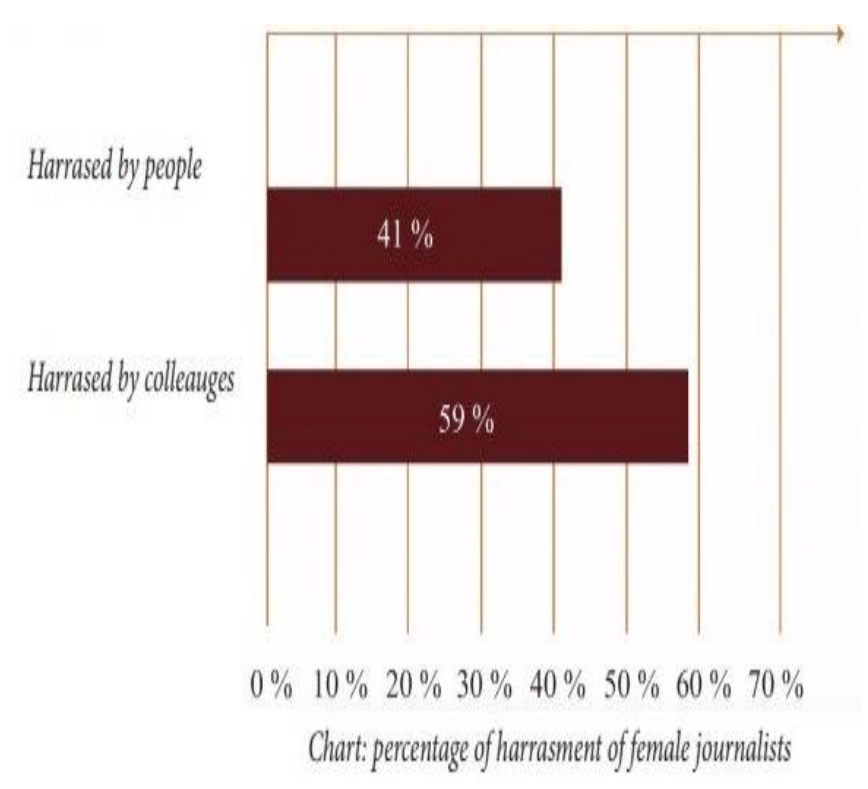

Figure 2

The chart shows the percentage of harassment of female journalists [21] [4]

\section{Working Team:}

The working team which was situated from different female journalists in Kabul, Balkh and Herat provinces discussed about number of factors of harassment and knowing the issue of sexual harassment in different working meetings. Despite the female journalists complain about the violation of Media law, they call the need of their safety very urgent for the consistency of their work. And the lack of the mechanism for the figuration and. following up creates broader problems which result. for violence and wrongful advantages. The working. team situated Kabul centre and provinces', Journalist's called the council meetings to suggest the prevention of violence towards female journalists.[21]

- Change and Improving the law in medias for the support of women.

- Employment of professionals and educated workers at managerial level at Media.

- Structuring and compilation of extra effective policies for the prevention of the sexual harassment.

- Commonsense.

- Creation of transparent system for the solvation of Sexual harassment's cases.

\section{Foundations for the Policy: The Constitution:}

According to the constitution of Afghanistan and other subordinating laws every kind of harassment is counted as crime. Every kind of discrimination among the Tribes of Afghanistan is prohibited, Men and women having equal rights towards the law. (22 Article of the constitution)

\section{The Holy Religion Of Islam:}

Every kind of discrimination connected to age, gender, tribe, ancestry, colour, religion, disability, political vision or social condition is absolutely prohibited in Islam. From Islamic point of view men and women having equal rights and insist that men and women must have honouring and noble connection to each other.

\section{Punitive Codes:}

The punitive codes published in official booklet investigated the issues of women and children and calling it as a crime, they have considered many certain cases and punishment and in some harsh pronounced cases imprisonment have been considered for the committed person. Based on Article 668 of the punitive code, if a person commits to harm the personality of someone by gestures, writings or illegal requests or harm their dignity need to be lead for punishment and this act is being called an oppressive act. Fortunately, the harassment of women and children is clearly called a crime and the committed person is going to lead punishment according to the code. And this law particularly indicated to some elements.

Words

\section{Gestures}

Writings

Illegal requests

In case these elements turn loss for the dignity of the women or children and result for their intimidation, mental pressure or insecurity is called harassment and the committed person is introduced for judicial follow up. The punitive codes not only indicated some harassing elements, but the legislature also considered to it. Based on Article 669 of the punitive code "If someone commit to harass women or children in public places or in any other place and in Public transportation, will be fined starting from 5000 Af to 10000 AFs". If the harassment happens in educational places, the committed persons will be fined up to 20000 Af. The punitive codes also considered some pronounced hard cases, if a teacher commits or an instructor, doctor, director to using own position and authority wrongfully commit for the crime it's called 'pronounced hard cases'. In such cases, the committed person is imprisoned for short term i.e. six months. 


\section{The Law For Prevention Of The Harassment Of Women And Children:}

The prevention law for sexual harassment was approved on October 282006 and before that the rule of the prevention of sexual harassment was approved on 2005, and due to the absentee of the executive guarantee it didn't have the ability for the convicting of the committed criminal.

The objectives of this law are to:

- Prevention of sexual harassment.

- Support from the harmed person of the incident.

- Providing of proper and academic environment.

- Access for learning and health services.

- Safeguarding the public awareness through social media.

\section{Definition Of The Sexual Harassment:}

Based on the article 4 of Law on Sexual Harassment is defined "if a person commits to harm the personality of a women or children by gestures, writings or illegal requests or harm their dignity or result for the mental pressure or bring intimidation or bring their reduction in social works, is being counted as criminal of sexual harassment and need to be lead for punishment "Based on article $16^{\text {th }}$ - the committee for struggling opposite of sexual harassment is situated from three members of the provincial council, and district council. And this compelled some ministries to struggle impressively opposite of harassment and carry on all of the works properly. It includes providing proper and workable environment, enhancement of public understanding and implementation of the cultural programs, arranging seminars, training workshop and conferences are the responsibilities of the ministries.

\section{Punishment:}

First: If the complaint relates to the activities of job, the committee refers different instructive issues and the administration take instructive actions based on available documents and testimonies. Second: In case the harassment happens in public transport or public places, the committed criminal is fined from 5000 to $10000 \mathrm{Af}$, and if the harassment happens in working place, schools and other educational centers or hospitals the committed person is fined starting 10000 to 20000 Af. If the crime pronounced hard or brings forward the possibility of repetition of the action or turn mental loss the committed trainer, doctor, instructor is sentenced to be imprison two months or six months.

\section{The Law Of Public Services:}

The law of public service convicts every kind of discrimination which happens through gender, race, sect or physical disability. $\left(10^{\text {th }}\right.$ article, Public Service Law)As well as the public services law convicts every kind of complaints about discrimination and safety which is caused for tribe, social stance, and sect, political or civil condition followed by heads and directors are prohibited and should be followed.

\section{The Law For The Prevention Of The Violence Against Women:}

Based on this law every kind of violence is a crime, no one has the right to commit for such crime in residency, government or non-government administration, public places, transport vehicles or in other places. At the occasion of committing the committed person is sentenced with punishment in the framework of the law. Despite above mentioned issues this law explained 23 other cases which can count sexual harassment and $14^{\text {th }}$ article of the law for the prevention of the violence against women calls the sexual harassment, a kind of violence which also carries a criminal responsibility.

\section{Practical Plan For Afghan Women:}

Practical plan for Afghan Women is provided by Afghan government in 2007 unless to secure Afghan women in public service working environment. One of the objective is to strengthen Afghan women and to bring gender equality unless to have part in official framework. The practical plan of Afghan women knows the discrimination towards women progress an extraordinary obstacle and it is counted to trample the human dignity and equality among the people.

\section{International Conventions:}

International conventions particularly those governments which having membership of the United Nations put vital and crucial commitments for struggling opposite of the discrimination of women. And there are many international documents which denotes the importance of elimination of discrimination and prevention of sexual harassment towards women. The ratification of the Convention of Elimination of Discrimination against Women (CEDAW) convention which is approved by the Assembly of United Nations in 1979. CEDAW defines the violence against women as a sensitive type of violence.

Considering this convention the following cases are 
Farooq Jan Mangal et. al/ Role of Media in Policy Making: Special reference to Afghanistan

called the stable standards for the definition of sexual harassment.

- When women face with some certain harassments, likewise harassment in working environment, this type of discrimination deeply affect equality in organization.

- Sexual harassment materials: Physically touching female, signs and colour related to sexual issues, showing sexy photos and videos and more.

\section{Aims Of The Policy:}

- Decreasing harassment in media.

- Creating fearless environment for female workers.

- Respect to women.

- Motivating female journalists to work in a proper environment.

- In working field establishing mechanism for violators.

\section{Solutions:}

A committee will be establish in each media to reduce harassment and there are a few ways to get access to all cases. This committee will solve all cases of harassment.

- Accepting the application and follow up.

- Receiving complaints through complaint box.

- To get more and more information and data meeting with the applicants.

- Specifying the type of harassment.

\section{Period Of Policy(Afghan Journal lists committee}

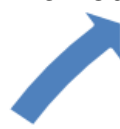

To observe

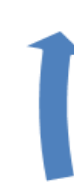

Executive perioud
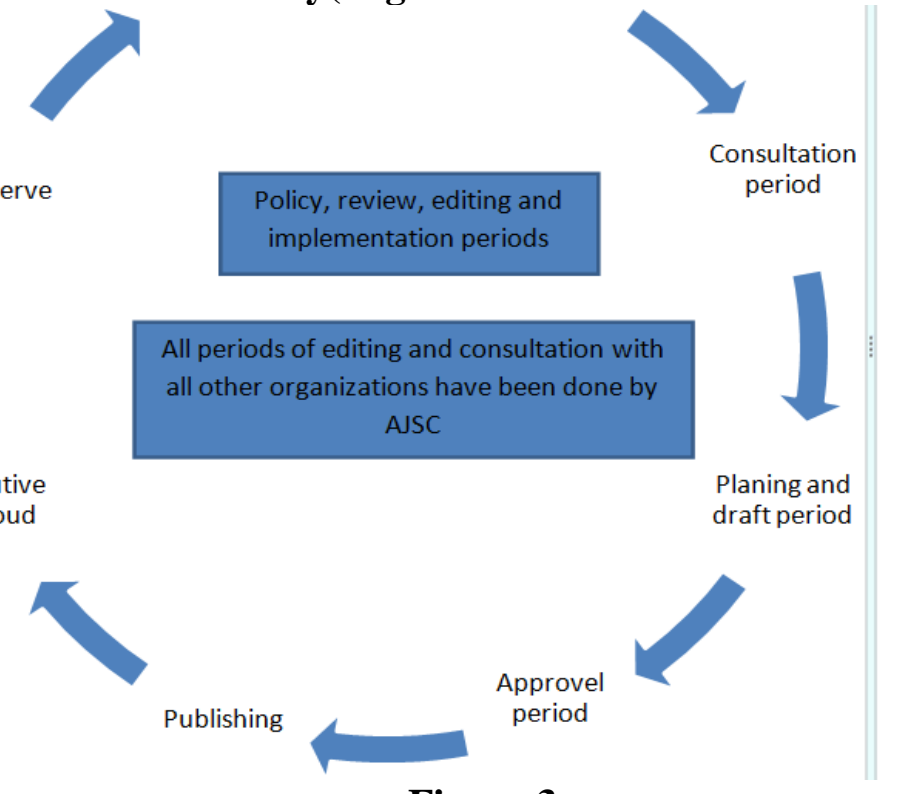

\section{Figure 3}

Charts shows the Policy, review, editing and implementation periods (Afghan Journalists Safety Committee)[4] [21]

\section{Conclusion:}

Mass media have an increasingly important role with respect to policymaking. Media are the public's largest source of information on public policy, and they are the single largest catalogue of political information, covering everything from administrative proceedings, policy change, public opinion, to political scandal. The main goal and aim is to explore how media reflects the policy process in. While it may be evident that media is a chief source of the historical documentation of politics and policy. Though, its role is undermine by theobserver or examined in the political science and public policy literature. The study is an opportunity to correct this imbalance in the public policy literature.

However, the role of media does not always effect the policy process, but occasionally influence the debate, either through affecting policymakers directly, systematically pushing policy alternatives, or through influencing citizens' opinion, their one constant role is to reflect the policy process, the actors within it, and public reactions to policies.

The work in the individual chapters examines how media reflected several aspects of the policy debate, including the language used in the media to (a) narrate policy change, (b) frame policies, and, (c) describe relationships between policies and policy actors.

Researchers often overlook the role where media

-acts as a mirror to the policy process in favor of

-more causal stories about the direct impact on individuals, parties, interests or external events on policymaking. But mass media both effect and reflect. Media content can, therefore be a valuable tool for understanding both politics and public policymaking. The premise of this study is to understand how media can (and do) influence policy and public opinion. This relationship is bidirectional and often creates feedback loops wherein policymakers and public opinion influence each other continually. However, the role of influencing policymakers, public opinion and decision-making tactics is not the only way in which we should regard media as important to political science and political communication. The study emphasise on how media mirrors the policy cycle - the long-term activities, the inputs and outcomes that explain and describe a policy domain.

\section{References}

1. (2014, 3 23). Afghanistan-media . Retrieved 9 10, 2019, from afghanistan-culture : http://www.afghanistan- 
Farooq Jan Mangal et. al/ Role of Media in Policy Making: Special reference to Afghanistan

culture.com/afghanistan-media.html

2. Ajsc. (2014, 09 05). Ajsc.af. Retrieved 03 29, 2018, from http://ajsc.af/commitment-of-thecandidates-of-the-presidential-elections-runoffphase-in-support-of-free-media-andjournalists/?lang=en

3. Ajsc. (2016). The reporting heroes - a study on the condition of afghan female journalists. Kabul : ajsc.

4. Ajsc. (2018, 03 28). Www.ajsc.af. Retrieved 03 28, 2018, from www.ajsc.af: http://ajsc.af/whowe-are/

5. Apaza, c. R., \& chang, y. (eds.). (2017). Whistleblowing in the world: government policy, mass media and the law. Springer.

6. Apaza, c. R., \& chang, y. (eds.). (2017). Whistleblowing in the world: government policy, mass media and the law. Springer.

7. Bennett, w. L. (1990). Toward a theory of press-state relations in the united states. Journal of communication, 40(2), 103-127.

8. Bennett, w. L., \& paletz, d. L. (eds.). (1994). Taken by storm: the media, public opinion, and us foreign policy in the gulf war. University of chicago press.

9. Cook, f. L., tyler, t. R., goetz, e. G., gordon, m. T., protess, d., leff, d. R., \& molotch, h. L. (1983). Media and agenda setting: effects on the public, interest group leaders, policy makers, and policy. Public opinion quarterly, 47(1), 16-35.

10. Dimaggio, a. R. (2017). The politics of persuasion: economic policy and media bias in the modern era. Suny press.

11. Gans, h. J. (2003). Democracy and the news. Oxford university press.

12. Graber, d. (2009). Mass media and american politics washington dc.

13. Kingdon, j. W., \& stano, e. (1984). Agendas, alternatives, and public policies (vol. 45, pp. 165-169). Boston: little, brown.

14. Koch-baumgarten, s., \& voltmer, k. (eds.). (2010). Public policy and the mass media: the interplay of mass communication and political decision making (vol. 66). Routledge.

15. Muhtaj. (2012, 07 03). Ariaye.com. Retrieved 03 28, 2018, from ariaye.com: http://www.ariaye.com/dari5/ejtemai/mohtaj3.ht $\underline{\mathrm{ml}}$

16. Olper, a., \& swinnen, j. (2013). Mass media and public policy: global evidence from agricultural policies. The world bank economic review, 27(3), 413-436.

17. Russell, a., dwidar, m., \& jones, b. D. (2016). The mass media and the policy process. In oxford research encyclopedia of politics.

18. Sapru, r. K. (2011). Public policy: art and craft of policy analysis. Phi learning pvt. Ltd.

19. Shanahan, e. A., mcbeth, m. K., hathaway, p. L., \& arnell, r. J. (2008). Conduit or contributor? The role of media in policy change theory. Policy sciences, 41(2), 115.

20. Tarzi, a. (2006, 4 28). Rferl. Retrieved 10 17, 2019, from radiofreeeurope radioliberty : https://www.rferl.org/a/1068023.html

21. Wyar, a. Q. (2018, 03 23). Role of ajsc in policy making . (f. J. Mangal, interviewer)

22. Zakem, v., saunders, p., hashimova, u., \& frier, p. K. (2017). Mapping russian media network: media's role in russian foreign policy and decision-making (no. Drm-2017u-015367-1rev). Cna analysis and solutions arlington va arlington united states. 